\title{
MAFOS: A Simple Tool for Monitoring the Performance of RAFOS Sound Sources in 咀e Ocean
}

\author{
Holger König, KATHY L. SCHUltZ TOKOS AND WALTER ZENK \\ Institut für Meereskunde an der Universität Kiel, Düsternbrooker, Kiel, Germany
}

(Manuscript received 10 October 1990, in final form 14 March 1991)

\begin{abstract}
A low-cost underwater sound recorder has been developed and tested. It is designed to receive signals from sound sources that serve as navigation aids for RAFOS floats. This moored version of the RAFOS float (MAFOS) can monitor sound sources over many months and several hundred kilometers. It thus improves RAFOS navigation accuracy by enabling corrections for potential long-term clock drifts of the sound sources. MAFOS can also provide information on the local variation in the speed of sound due to natural hydrographic variability. In a first test, this usefulness has been proven and a warm, salty inhomogenity that traveled through a soundsource mooring array in the Iberian Basin has been observed.
\end{abstract}

\section{Introduction}

The ocean is becoming increasingly ensonified as oceanographers utilize sound propagation as an efficient method of measuring the ocean's physical properties. With the advent of World Ocean Circulation Experiment (WOCE) and its planned subsurface float and possible tomography programs, there is a growing need to monitor the performance of moored sound sources used in such experiments. At the Institut für Meereskunde (If M), Kiel, a low-cost monitoring instrument has been successfully developed.

The RAFOS (SOFAR, sound fixing and ranging, spelled backwards) system, originally developed at the University of Rhode Island, has already demonstrated its general usefulness in studies of large-scale ocean currents (Rossby et al. 1986; Bower and Rossby 1989, for example). Since 1989, the If $M$ has been adopting the well-proven RAFOS system (Zenk 1990). It consists of acoustically tracked, neutrally buoyant floats that are deployed within an array of moored sound sources. RAFOS floats are designed as low-cost expendable instruments. A borosilicate glass pipe $0.1 \mathrm{~m}$ $\times 1.5 \mathrm{~m}$ long contains electronic components necessary for listening to coded signals from fixed sound sources. The subsurface floats record the arrival times of the sound signals together with temperature and hydrostatic pressure. Their data are recovered via the Argos satellite system after the floats have returned to the sea surface on a predetermined time schedule. Typical

Corresponding author address: Dr. Walter Zenk, Institut für Meereskunde an der Universität Kiel, Düsternbrooker Weg 20, 2300 Kiel 1, Germany. mission lengths are between 1 and 2 months, although they have operated successfully for 18 months.

The whole RAFOS system relies critically on the reliable performance of the sound sources. The sound sources are arranged to provide maximum spatial coverage, taking into consideration the local flow field, the topography, and the hydrographic conditions. According to the manufacturer's specification (Webb Research Corporation, Falmouth, Massachusetts), their lifetime is expected to be at least three years, depending on battery choice and mechanical stress conditions on the mooring components, such as the effects of corrosion or fish bites. At least three sources are essential for an unequivocal determination of float position. However, two signals are usually sufficient, since the deployment location is well known and can be used to exclude the positional ambiguity.

This paper deals with the new construction of and first experiences with a moored instrument for monitoring the performance of RAFOS sound sources. We call this device, which has been derived from a standard RAFOS float, MAFOS, standing for moored RAFOS. Beginning with a short description of the needs for MAFOS, we present a physical description of the instrument. The practical results are then summarized from a first deployment and future plans are discussed.

\section{Purpose}

The primary aim in the development of the MAFOS instrument was to definitively determine the timing accuracy (or existence) of three RAFOS sound sources moored in the Iberian Basin. Each was programed to transmit three times per day at 8-h intervals. The quality of their performance was questionable in light of a 
potential timing problem discovered and relayed to us by the manufacturer. A small drift within a soundsource clock is allowable only when it is constant and known exactly.

The secondary purpose of the MAFOS mooring was to test the "float" itself. The instrument is only a slight modification of the generation of German RAFOS floats [see Rossby et al. (1986) for a description of the original RAFOS instrument] to be used in studies of the Mediterranean outflow, and no in situ test of this particular variant had been made. The FORTH software, identical to that used to control the operation of the RAFOS floats, was tested under operating conditions in real time. In addition, the 2-month deployment provided necessary information about the performance of the hardware: pressure transducer, hydrophone, and end plate, for example.

\section{Instrument description}

\section{a. Mechanics}

There are two fundamental differences between a RAFOS float and a MAFOS monitor. First, MAFOS, which is placed on a recoverable deep-sea mooring, does not need an Argos transmitter or antenna. Second, the ballast release mechanism of the RAFOS float is unnecessary. A MAFOS monitor is shown in Fig. 1. It is housed in a borosilicate glass pipe nearly identical to that used for RAFOS floats. However, is it only 70 $\mathrm{cm}$ long, i.e., about half the length of a float. The lower end is closed with a hard anodized aluminium end plate attached with silicon rubber to the glass pipe. An additional seal is not necessary.

In the end plate there are three "through-hull" fittings: one for the pressure transducer, one for the hy-

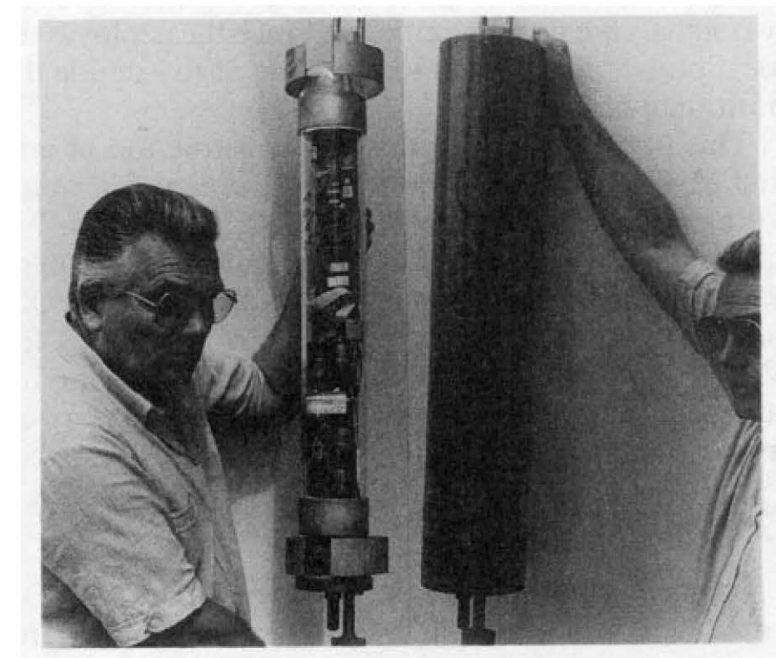

FIG. 1. The MAFOS monitor without (left) and with (right) the protecting PVC tube. The glass pipe, similar to an oversized test tube, is attached to a mooring support. The hydrophone at the lower end is exposed to incoming signals. drophone, and one for an external RS232 connection. The pressure transducer is located in the middle of the end plate. It converts the hydrostatic pressure into a frequency-modulated signal suitable for electronic counting. Calibration of the transducer network is made with a dead weight tester. The hydrophore is mounted on the end plate to receive the signals from the moored sound sources. A four-pin connector is mounted in the third drill hole. It is used for connection to a computer terminal to program the instrument's mission and, afterwards, for recovery of recorded data. Since the thermistor is located on the analog circuit board, no extra machining of the end plate is necessary for temperature measurement. The whole thermistor network is calibrated in a climate chamber, where a thermal time constant ( $63 \%$ change) of 90 min was also determined. Before deployment of the MAFOS monitor, its glass pipe is protected with a PVC tube. A stainless steel support is attached to the glass pipe for mounting the MAFOS monitor to the mooring system (see Fig. 1).

\section{b. Electronics}

The electronic circuits are contained on two boards manufactured by Bathy Systems, Incorporated, West Kingston, Rhode Island. Aquisition of pressure, temperature, and sound signals occurs on the analog board. The analog-digital conversion is made on the digital board. The heart of all MAFOS (and RAFOS) devices is the microprocessor, Motorola 6805E3E. It regulates and monitors all events of the MAFOS mission. Data can be stored in two RAM (random access memory) banks.

The MAFOS operation is performed by FORTH code (Carter 1986), which is stored in two PROMs iprogrammable read only memory). As in the RAFOS floats, mission length is determined by programming the total number of listening windows and the number of listening windows per day. A listening window is the time interval that the MAFOS monitor is in the receiving mode (on-time). The time of arrival (travel time of incoming signals) is measured with respect to the beginning of each listening window.

The sound-source signals are recognized with a hardware filter and the microprocessor compares the received signals to the expected one. According to the match, each travel time is associated with a relative correlation height, which is a measure of signal significance. Within each listening window the two highest correlated travel times, together with their correlation heights, are stored in RAM. The length of the listening window can be changed according to the mission requirements. After the on-time, the MAFOS goes into a sleep mode (off-time), the duration of which is also chosen by the user.

After every third window, a temperature and a pressure measurement are taken. Both temperature and 
pressure are digitized separately and stored as 2-byte integers, resulting in a resolution of $0.01{ }^{\circ} \mathrm{C}$ and 0.1 $\mathrm{db}$, respectively. Three listening windows with one temperature and pressure measurement is called a measurement cycle. It is 22 bytes long. Since the FORTH code uses around 700 bytes of RAM, there are approximately 7400 bytes left for data storage. To prevent data loss by an accidental power loss, the RAM is backed up by a battery-powered socket. Once the mooring is recovered, a computer terminal is connected to the MAFOS monitor, the RAM content is dumped on the external computer disk, and the data are ready for subsequent processing.

\section{A first experiment}

A first MAFOS mooring was set at $39^{\circ} \mathrm{N}, 14^{\circ} \mathrm{W}$ on 19 March 1990, about one year after the deployment of three sound sources, $N$ (northern), $S$ (southern), and $W$ (western), in the Iberian Basin. It was located within the triangular sound source array, $550 \mathrm{~km}$ ( $\sim 366 \mathrm{~s}$ travel time of sound) from the farthest sound source (Fig. 2). The complete MAFOS mooring is shown in Fig. 3. For redundancy, two MAFOS monitors (number 86 and number 87 ) were used. Nominally, MAFOS number 86 was located at $780 \mathrm{~m}$, number 87 at $800 \mathrm{~m}$ depth. A total of $2217^{\prime \prime}$ glass balls provided sufficient buoyancy for the mooring. An acoustic release $60 \mathrm{~m}$ above the $700-\mathrm{kg}$ anchor enabled the recovery of the mooring after the 2-month deployment.

Since it was not certain that the sound sources were transmitting at their programmed time, the MAFOS monitors were programed for nearly continuous listening, to ensure that even horrendously early or late signals would be received. For this, a 23-min on-time with 7-min off-time listening schedule ( 16 measurement cycles per day) was chosen. With this listening schedule, the mission length, limited only by data storage space, was 20 days. Normally, the approximate time of signal transmission is known, which allows fewer listening windows per day, and much longer mission lengths are possible. In addition, utilizing the second RAM for data storage approximately doubles the storage capacity. For example, with one measurement cycle per day, it is possible to monitor the sound sources for 630 days.

The mooring was recovered on 17 May 1990. Immediately after recovery, data were transferred via the terminal connection to a personal computer. Here, the pressure and temperature calibration coefficients were applied, and the measured MAFOS clock drifts were removed before analysis.

\section{a. Technical results}

The first MAFOS mooring was highly successful. With it, we were able to determine that two of the three

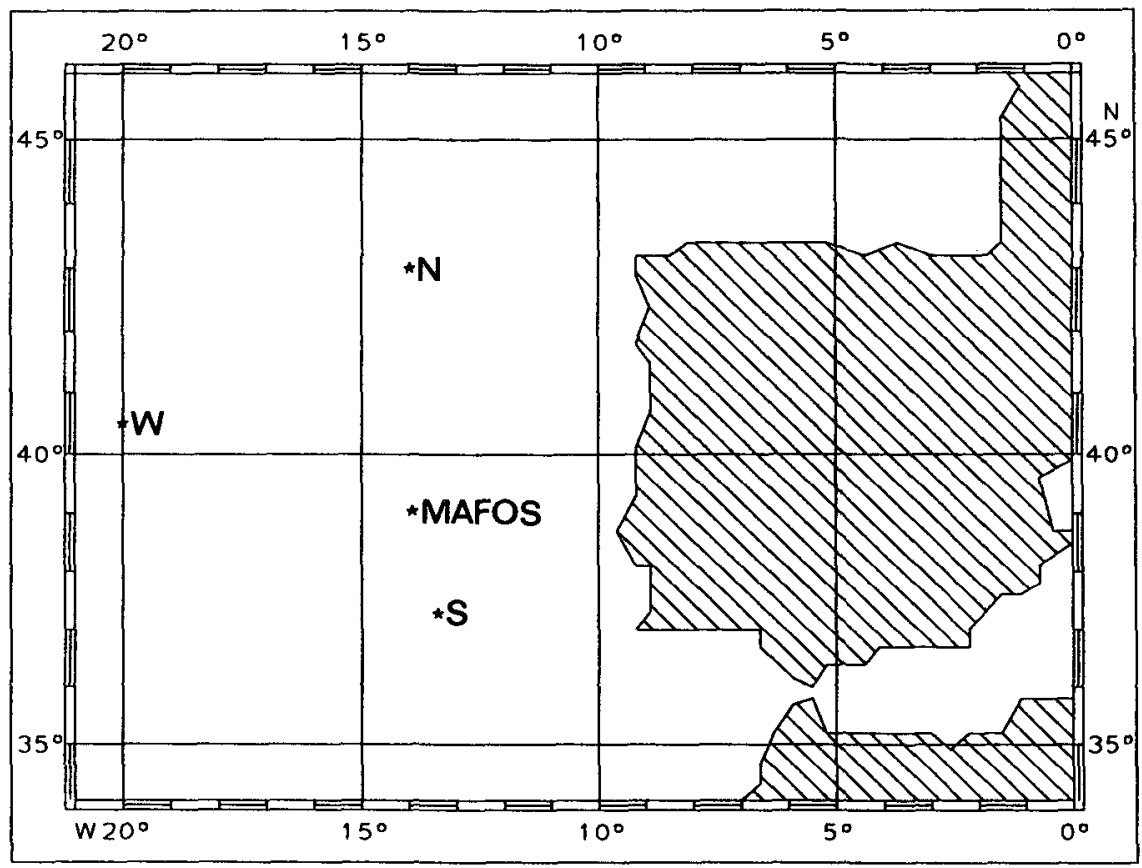

FIG. 2. Mooring array in the Iberian Basin. The mooring positions of sound sources $N, S, W$, and MAFOS are shown. The distance from MAFOS to $N$ was $440 \mathrm{~km}$, to $S 201 \mathrm{~km}$, and to $W$ $546 \mathrm{~km}$. Under the assumption of an averaged speed of sound of $1500 \mathrm{~m} \mathrm{~s}^{-1}$, this results in travel times of sound from $N$ of $\sim 293 \mathrm{~s}$, from $S \sim 135 \mathrm{~s}$, and from $W$ around $364 \mathrm{~s}$. 


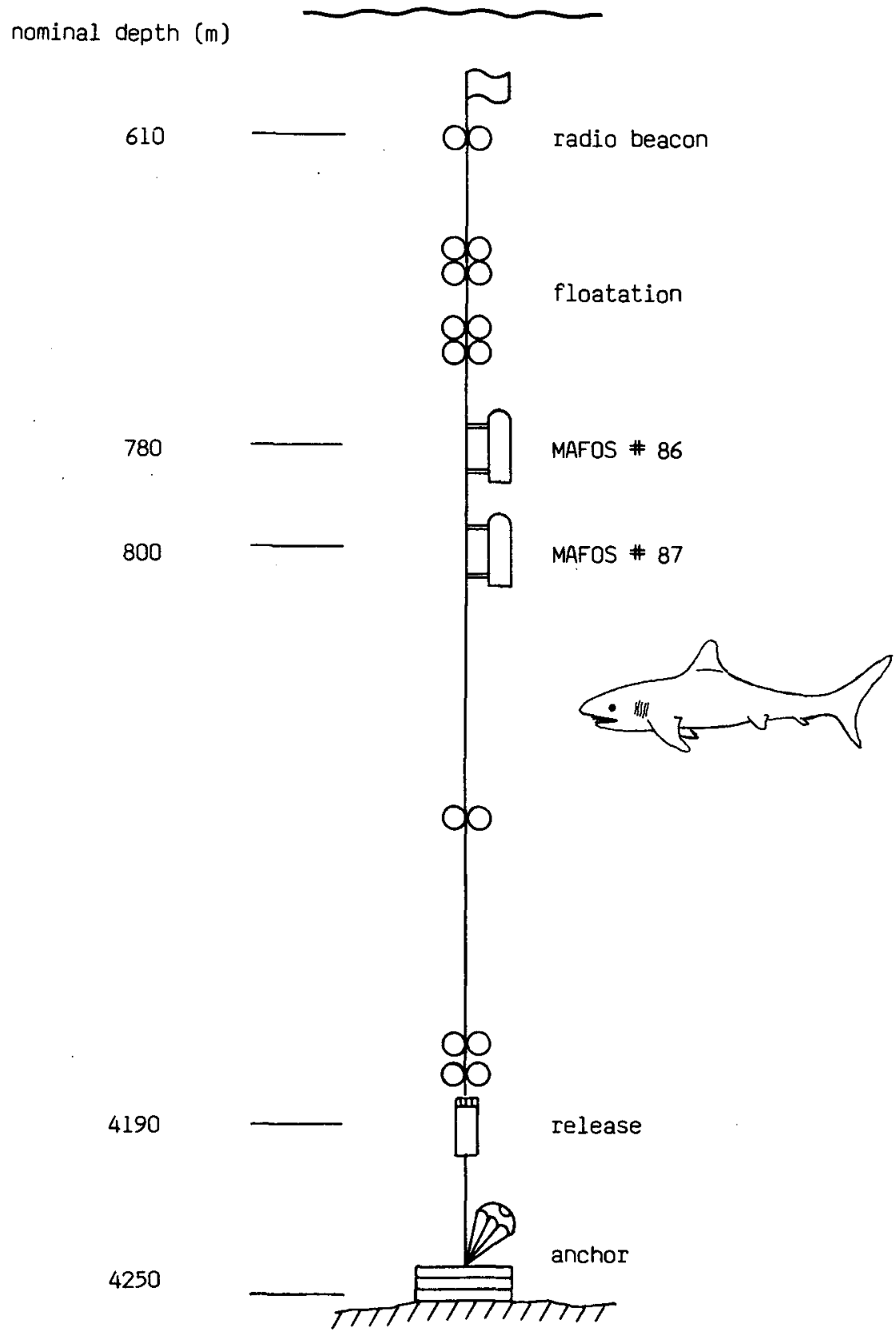

FIG. 3. Schematic diagram of If M mooring 332. Both MAFOS instruments, $20 \mathrm{~m}$ apart, were moored near the thermal sound channel at $800 \mathrm{~m}$ depth in the Iberian Basin from March to May 1990.

sound sources were operating properly during the MAFOS deployment.

With the chosen listening schedule, each MAFOS stored 96 travel times per day. If the 3 sound sources transmitted three times a day each, and all transmissions were received by the MAFOS, 9 travel times would be signals and 87 would be ambient noise. A preliminary inspection of our data showed that 2 sound sources were working properly. Therefore Fig. 4a shows the time series of only the highest correlated signal during the listening window in which the signals were expected from the $N$ and $S$ sound sources. Hence, for clarity, only 6 travel times per day, instead of 96 , are shown for each MAFOS monitor. Although there is some scatter in the data (discussed below), the expected signals, labeled $N$ and $S$ in the diagram, are recognized by nearly constant time of arrival, correct travel time, and correlation height (not shown). 


\section{MAFOS \# 86 and 87}
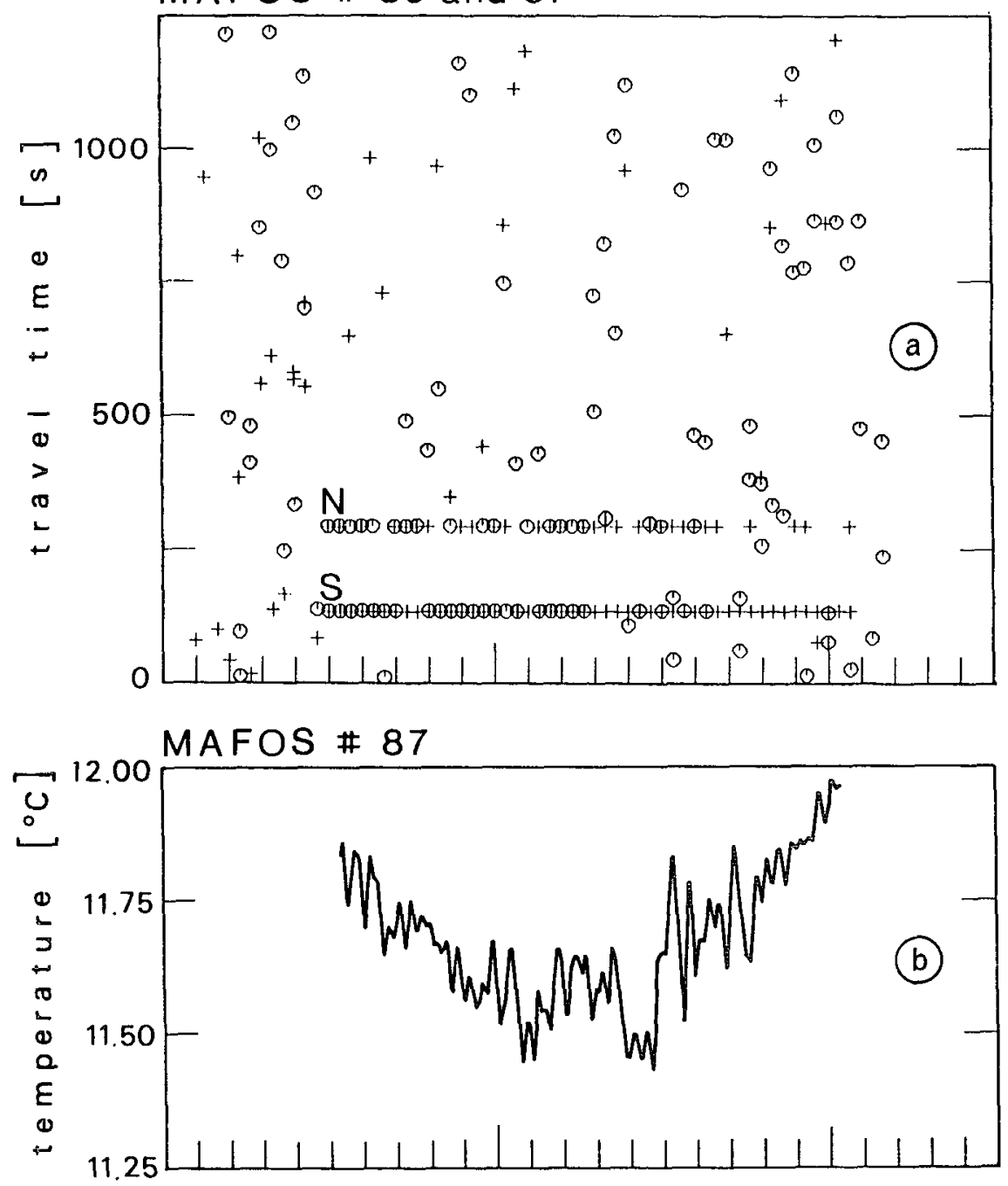

MAFOS \# 87

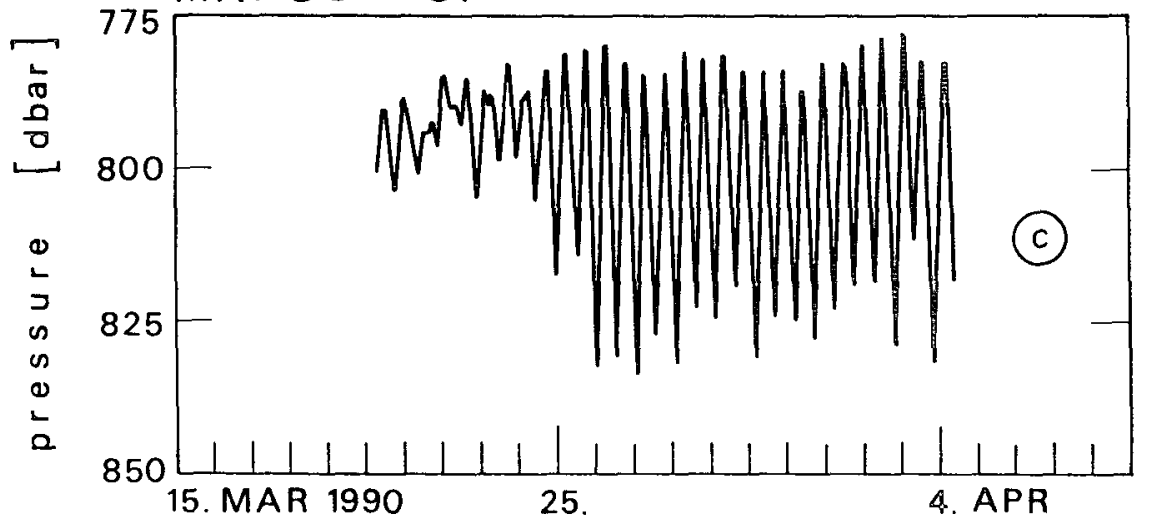

FIG. 4. (a) Time of arrival of the highest correlated signals received by each MAFOS monitor $(+=$ MAFOS number $86 ; 0=$ MAFOS number 87$)$ measured in seconds after the transmission times of the two sound sources, $N$ and $S$. The signals from the sound sources are labeled and recognized by the constant time of arrival. (b) Temperature and (c) pressure time series of MAFOS number 87. Predominant fluctuations in both parameters are caused by semidiurnal tidal currents. After a period of general temperature decrease and relatively small pressure fluctuations, a pronounced temperature rise is observed after 25 March. This temperature increase occurs simultaneously with large depth fluctuations recorded by both instruments, which might be caused by the passing of a meddy. 
The scatter in the diagram is ambient noise, recorded during those windows in which the sound-source signal was not received. The noise is easily recognized as such by its random travel times and low correlation heights (not shown). The lack of signal reception and consequent recording of noise can be attributed to hydrographic conditions or occassional failure of the hydrophone or sound source transducer and can be ignored.

For example, to describe Fig. 4a in more detail, on 20 March, MAFOS number 87 heard sound source $S$ (at $\sim 135 \mathrm{~s}$ ) and sound source $N($ at $\sim 290 \mathrm{~s}$ ) three times each, resulting in six " $o$ " data points on that day. On the other hand, MAFOS number 86 received all three transmissions of sound source $S$, but only two transmissions from sound source $N$ (resulting in five good "+" data points). The third time of arrival for $N(\sim 630 \mathrm{~s})$ is noise.

The correct travel times of signals from $N$ and $S$, along with the lack of any appreciable change over 20 days (clock drift), shows these two sound sources still functioned very well after 1 year of operation. Upon examination of all the nearly continuous data recorded throughout the 20-day period, no evidence of a third signal $(W)$ was found. The lack of a third consistent time of arrival and only noise-level correlation heights indicate $W$ was not transmitting on any time schedule. Upon later release of the $W$ mooring, the lack of reception was not without good reason. The sound source had been severed from its mooring sometime before 19 March 1990, the date of the MAFOS deployment.

Each MAFOS received sound source $S$ better than $N$, which is shown in generally higher correlations and has a greater number of received signals (compare number of points near $135 \mathrm{~s}$ to those near $290 \mathrm{~s}$, Fig. 4a). The MAFOS mooring was nearly twice as close to $S(201 \mathrm{~km})$ as it was to $N(440 \mathrm{~km})$. Although we would (conservatively) expect to clearly receive signals from over $1000 \mathrm{~km}$ away in the SOFAR channel, sound propagation in this region is complex (Zenk and Armi 1990) and may account for the weaker reception. After 25 March 1990, a salty feature, possibly an eddy of Mediterraenan outflow water called a meddy, passed through the array, as will be discussed below. Newton (1989) has shown that the local propagation of sound can be dramatically affected by the presence of meddies. It is possible that the passage of this meddy may be related to the weaker reception near the end of the time series. So, while a single MAFOS mooring in a less complex region should be sufficient to cover a radius of about $1000-1500 \mathrm{~km}$, further work is planned in the Iberian Basin to determine sound propagation characteristics in this particular region.

The MAFOS monitors' performances were not identical. Overall, correlation heights recorded in MAFOS number 87 were lower than in MAFOS number 86. Also, closer examination of Fig. 4a shows that MAFOS number 87 stopped identifying signals altogether on 31 March 1990, five days before the mission ended. Since the temperature and pressure re:ords are complete, we suspect a hydrophone failure.

Besides the primary information concerning the sound sources' existence and clock drifts, useful technical information was gained about the hardware used in the MAFOS (and therefore RAFOS) construction. When the MAFOS monitors were recovered, some corrosion on one of them was found where seawater had seeped through the silicone glue attaching the end plate. This may have been caused by electrolysis between the aluminium end plate and the stainless steel brackets used to attach the instruments to the morring. In the future, more care must be taken to use inert materials to avoid corrosion problems.

Between both instruments, the pressure and temperature records are highly correlated (see Table 1 ). However, each pressure record had independent, irregular but consistently large and positive spikes. The cause of these spikes is currently being investigated. The temperature measurement was error-free, and its correlation to the passing of the salty blob is discussed later.

\section{b. Oceanographic findings}

The primary aim for the introduction of the RAFOS float technology at If $M$ is the observation of the Mediterranean water tongue, with special emphasis on the formation and propagation of Mediterranean salt lenses in the Iberian Basin. Theoretical studies by Käse et al.

TABLE 1. Statistics of unfiltered data from mooring site 332 $\left(39^{\circ} \mathrm{N}, 14^{\circ} \mathrm{W}\right)$ between 19 March and 5 April 1990.

\begin{tabular}{|c|c|c|}
\hline & $\begin{array}{c}\text { MAFOS } \\
\text { number } 86\end{array}$ & $\begin{array}{c}\text { MAl'OS } \\
\text { number } 87\end{array}$ \\
\hline Nominal depth (m) & 780 & 800 \\
\hline $\begin{array}{c}\text { Mean pressure } \pm \text { standard } \\
\text { deviation }(\mathrm{db})\end{array}$ & $776 \pm 15.7$ & $799 \pm 14.5$ \\
\hline $\begin{array}{l}\text { Pressure-correlation } \\
\text { number } 86 / \text { number } 87\end{array}$ & \multicolumn{2}{|c|}{0.86} \\
\hline $\begin{array}{l}\text { Pressure at zero current (db) } \\
\text { Meddy event }>25 \text { March } \\
1990\end{array}$ & 758 & $78: 1$ \\
\hline $\begin{array}{l}\text { Pressure at average } \\
\text { minimum current (db) }\end{array}$ & 762 & 78.5 \\
\hline $\begin{array}{l}\text { Pressure at average } \\
\text { current }(\mathrm{db})\end{array}$ & 781 & 80.4 \\
\hline $\begin{array}{l}\text { Pressure at average } \\
\text { maximum current (db) }\end{array}$ & 800 & 823 \\
\hline $\begin{array}{l}\text { Mean temperature } \pm \\
\text { standard deviation } \\
\left({ }^{\circ} \mathrm{C}\right)\end{array}$ & $11.76 \pm 0.13$ & $11.69 \pm 0.14$ \\
\hline $\begin{array}{l}\text { Temperature correlation } \\
\text { number } 86 / \text { number } 87\end{array}$ & & \\
\hline $\begin{array}{l}T \text { minimum }\left({ }^{\circ} \mathrm{C}\right) \\
T \text { maximum }\left({ }^{\circ} \mathrm{C}\right)\end{array}$ & $\begin{array}{l}11.42 \\
12.00\end{array}$ & $\begin{array}{l}11.44 \\
12.04\end{array}$ \\
\hline $\begin{array}{c}\text { Meddy event }>25 \text { March } \\
1990 \\
T \text { change }\left({ }^{\circ} \mathrm{C}\right)\end{array}$ & $13.15 \rightarrow 13.73$ & $13.05 \rightarrow 13.58$ \\
\hline
\end{tabular}


(1989) have demonstrated the possibility of meddy "formation by baroclinic instability of northward middepth jet of Mediterranean water and by fragmentation of larger-scale Mediterranean water blobs." During the MAFOS deployment cruise in March 1990, intensive CTD studies have shown the presence of a large, salty feature about $80 \mathrm{~km}$ northeast of the mooring site. Its core salinity exceeded the typical background station in the area by 0.45 practical salinity units (Käse and Hinrichsen, personal communication ). Two months later, when the FS Poseidon returned to the mooring site for recovery, it was found that the large salt anomaly had migrated an estimated $100 \mathrm{~km}$ westward.

With this hydrographic evidence, we expect the highly saline feature, which we call a meddy, to have moved through the mooring site. This situation resembles the scenario that Armi and Zenk (1984) described when the long-term current meter mooring, KIEL276, was hit by "lens 3" in June 1981. A first inspection of our new temperature and pressure time series from MAFOS (mooring number 332) reveals a clear signal around and after 25 March 1990. Both instruments display a trend toward higher pressure and temperature values, and both pressure records show well-developed oscillations with an amplitude of $\sim 38 \mathrm{db}$. For readability, only the temperature record (Fig. 4b) and the pressure record (Fig. 4c) of MAFOS number 87 are shown. Table 1 summarizes the basic statistics of the original time series of both instruments. As seen in the pressure record, without recognizable delay the

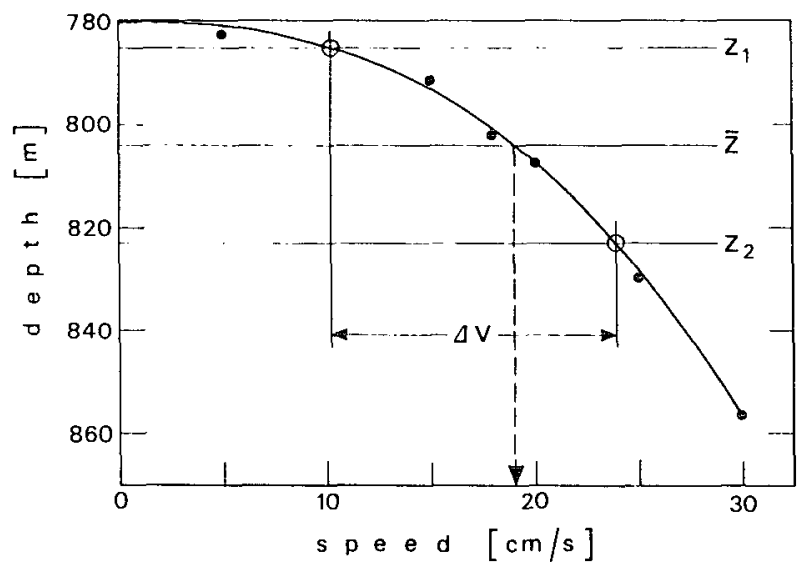

FIG. 5. Hypothetical mooring depression $Z$ at the varying level of MAFOS monitor number 87 in the Iberian Basin. Obviously strong drag forces acted on the mooring as a consequence of the passage of the meddy after 25 March 1990 (see Fig. 4b,c). For the calculation, various shear-free currents (dots) above $1200 \mathrm{~m}$ depth were assumed, which decayed to $5 \mathrm{~cm} \mathrm{~s}^{-1}$ at $1700 \mathrm{~m}$ and decreased linearly to zero at the bottom. Instrument depth oscillated between $Z_{1}$ and $Z_{2}$ around an average $\bar{Z}$, which is in good agreement with pressure values shown in Table 1. Associated with these depth variations are tidal speed fluctuations $\Delta V$ of $O\left(15 \mathrm{~cm} \mathrm{~s}^{-1}\right)$. This result resembles earlier mooring observations discussed and shown by Armi and Zenk (1984, their Fig. 14) for the central Canary Basin.
MAFOS mooring apparently followed the semidiurnal tidal currents, superimposed on the azimuthal speed of the meddy. Under this assumption and with earlier observations of typical vertical meddy velocity structures (Schultz Tokos and Rossby 1991), the suspicion of a meddy passage through our mooring array is indirectly confirmed. With the If $M$ numerical program for the statics of single-point moorings, STASIP (Breitenbach and Schröder 1982), we analyzed the submergence of MAFOS number 87 due to the meddy impact. STASIP predicts the stationary response of deep-sea moorings by considering mooring configuration and drag forces caused by hypothetical current profiles (Schröder 1982). The average pressure excursions caused by the semidiurnal tidal current from the mean level of $804 \mathrm{db}$ (see Table 1) and the mooring configuration (Fig. 3) are used together with an assumed reference velocity profile (Armi and Zenk 1984) as input parameters for STASIP. Inferred tidal speed fluctuations, $\Delta V$ of $O\left(15 \mathrm{~cm} \mathrm{~s}^{-1}\right)$, are obtained around a meddy mean azimuthal speed of about $18 \mathrm{~cm} \mathrm{~s}^{-1}$ (Fig. 5). Under the given circumstances this result is very encouraging. It is not inconsistent with meddy speeds observed earlier and shows, together with the temperature increase, new evidence for the possible passage of a meddy through a mooring site in the deep Iberian Basin.

\section{Conclusion}

An instrument type has been built and successfully tested that monitors RAFOS sound sources in the ocean. Since this device, called a MAFOS monitor, is derived from a standard (i.e., expendable) RAFOS float (Rossby et al. 1986), it is a low-cost instrument that also measures local temperature and vertical mooring motions. Although its pressure measurement cannot replace a moored current meter, we have demonstrated its usefulness for oceanographic purposes. We recommend the deployment of MAFOS monitors or equivalent instruments for future middepth Lagrangian observations, especially with the advent of WOCE float projects. Their ease of production and low price justify the monitoring of moored sound sources (and their potential clock drifts). In addition, they can ensure that large quantities of RAFOS floats will not be launched without proper ensonification of the ocean region.

Acknowledgments. This work has been supported by Deutsche Forschungsgemeinschaft, Bonn (SFB 133). We thank Kapitän Gross and his crew for the help onboard FS Poseidon during deployment and recovery of our first MAFOS mooring. We further thank $T$. Rossby for his assistance with the RAFOS technology at If $M$ Kiel. It is with pleasure that we acknowledge the work of U. Huenninghaus and P. Meyer, who were in charge of the mechanical and electronic stages of development of this project. 


\section{REFERENCES}

Armi, L., and W. Zenk, 1984: Large lenses of highly saline Mediterranean water. $J$. Phys. Oceanogr., 14, 1560-1576.

Bower, A., and T. Rossby, 1989: Evidence of cross-frontal exchange processes in the Gulf Stream based on isopycnal RAFOS float data. J. Phys. Oceanogr., 19, 1177-1190.

Breitenbach, J., and M. Schröder, 1982: Anleitung zur Benutzung des Rechenprogramms STASIP. Ber. Inst. f. Meeresk. Kiel, 109, $90 \mathrm{pp}$.

Carter, E., 1986: Forth Goes to Sea. Dr. Dobb's Journal of Software Tools, M\&T Publishing, 40-44.

Käse, R. H., A. Beckmann and H. H. Hinrichsen, 1989: Observational evidences of salt lens formation in the Iberian Basin. $J$. Geophys. Res., 94, 4905-4912.
Newton, S. J., 1989: The sound field disturbance caused by a "Mediterranean salt lens. M. Sc. thesis, Royal Roads Military College, Victoria, BC, $91 \mathrm{pp}$.

Rossby, T., D. Dorson and J. Fontaine, 1986: The RAFOS system. J. Atmos. Oceanic Technol., 3, 672-679.

Schultz Tokos, K. L., and T. Rossby, 1991: Kinematics and dynamics of a Mediterranean salt lens. J. Phys. Oceanogr., 21, 879-892.

Schröder, M., 1982: Das statische Verhalten von Einpunktvirrankerungen bei Anströmung. Ber. Inst. f. Meeresk. Kiel, 1108, 165 pp.

Zenk, W., 1990: "German RAFOS" project. ARGOS Newslett. 39, 13-17.

—- and L. Armi, 1990: The complex spreading pattern of Mediterranean water off the Portuguese continental slope. Doep-Sea Res., 37, 1805-1823. 